\title{
I 006 Extra cardiac abnormalities on coronary MR angiography in the MESA atudy: frequency and significance
} Jens Vogel-Claussen*1, Robson Macedo', Nishant Gupta1, Debiao Li², James Carr ${ }^{2}$, Kiang Liu ${ }^{2}$, Moyses Szklo ${ }^{3}$, Joao Lima ${ }^{1}$ and David A Bluemke ${ }^{1}$

\author{
Address: ${ }^{1}$ Johns Hopkins Hospital, Baltimore, USA, ${ }^{2}$ Northwestern University, Chicago, IL, USA and ${ }^{3}$ Johns Hopkins Bloomberg School of Public \\ Health, Baltimore, USA \\ * Corresponding author
}

from I I th Annual SCMR Scientific Sessions

Los Angeles, CA, USA. I-3 February 2008

Published: 22 October 2008

Journal of Cardiovascular Magnetic Resonance 2008, IO(Suppl I):AI3I doi:I0.II86/I532-429X-I0-SI-AI3I

This abstract is available from: http://jcmr-online.com/content/I0/SI/AI3।

(c) 2008 Vogel-Claussen et al; licensee BioMed Central Ltd.

\section{Introduction}

The frequency and significance of extra cardiac abnormalities associated with coronary computed tomography angiography (CTA) have been described, but extra cardiac findings associated with coronary magnetic resonance angiography (MRA) have not been reported. The purpose of the study was to describe extra cardiac findings in subjects undergoing coronary magnetic resonance angiography (MRA) in the MESA (Multi Ethnic Study of Atherosclerosis) population and to define their clinical significance.

\section{Materials and methods}

134 participants (63 men and 71 women) with a mean age of $67 \pm 9.4$ years (age range $41-89$ years) underwent coronary MRA from the MESA population. The first 11 subjects were evaluated using a $1.5 \mathrm{~T}$ whole-body MRI system (Signa CVi, General Electric Medical Systems, Waukesha, WI). Consecutive 123 subjects were imaged on a 1.5 $\mathrm{T}$ whole-body clinical scanner (Avanto, Siemens Medical Solutions, Erlangen, Germany). Three plane scout images/ localizing images and steady state free precession coronary MRA images were acquired using either breath-hold technique $(n=23)$ or free breathing whole heart technique $(\mathrm{n}=111)$. The images were read by two experienced radiologists. The findings were classified based on their clinical significance: 0 no follow up/referral, but reportable, 1 follow-up MRI exam to ensure stability of finding, 2 additional imaging test needed to evaluate the abnormality, 3 emergent referral/additional imaging test.

\section{Results}

Extra cardiac findings were detected in 61/134 participants $(45.5 \%)$. None of the subjects required emergent referral/additional imaging test. Of all patients 4/134 (3.0\%) needed either a follow up exam to ensure stability of finding ( 1 , ascending aortic root dilatation $>4.5 \mathrm{~cm})$ or a routine referral/additional imaging test $(3$, moderate enlargement of main pulmonary artery, $2 \mathrm{~cm}$ lung nodule, renal hydronephrosis). Most of the extra cardiac findings (58/61 pt, 95.1\%) required no follow up/referral unless related to other patient health issues, because the abnormalities were well characterized by the MRI examination (i.e. liver cyst/hemangioma, hiatal hernia, stable vertebral compression fracture, duplication cyst, bulla in lung, cysts in breast, colonic diverticula).

\section{Conclusion}

Non cardiac abnormalities are very commonly identified on coronary MRA examinations. Familiarity with non cardiac MRI interpretation may help avoid unnecessary testing that may otherwise accompany inconclusive identification of extra cardiac abnormalities incidentally detected on coronary MRA. 